\title{
Temporary Rise in Blood Thrombogenicity in Patients with Acute Myocardial Infarction
}

\author{
Shumpei Kosugi1@ Yasunori Ueda ${ }^{1}{ }^{10}$ Haruhiko Abe $^{1}$ Kuniyasu Ikeoka ${ }^{1}$ Tsuyoshi Mishima ${ }^{1}$ \\ Tatsuhisa Ozaki ${ }^{1}$ Kohtaro Takayasu ${ }^{1}$ Takuya Ohashi ${ }^{1}$ Haruya Yamane ${ }^{1}$ Masayuki Nakamura ${ }^{1}$ \\ Takashi Fukushima $^{1}$ Kohei Horiuchi ${ }^{1}$ Takashi lehara ${ }^{1}$ Satoshi Osaki ${ }^{1}$ Kazuki Ozato $^{1}$ Koichi Inoue ${ }^{1}$ \\ Yukihiro Koretsune $^{1}$ Yasushi Matsumura ${ }^{1}$ \\ ${ }^{1}$ Cardiovascular Division, National Hospital Organization Osaka \\ National Hospital, Osaka, Japan \\ TH Open 2022;6:e26-e32. \\ Address for correspondence Yasunori Ueda, MD, PhD, FACC, FESC, \\ FJCC, FJCA, Cardiovascular Division, National Hospital Organization \\ Osaka National Hospital, 2-1-14 Hoenzaka, Chuo-ku, Osaka 540-0006, \\ Japan (e-mail: yellowplaque@gmail.com).
}

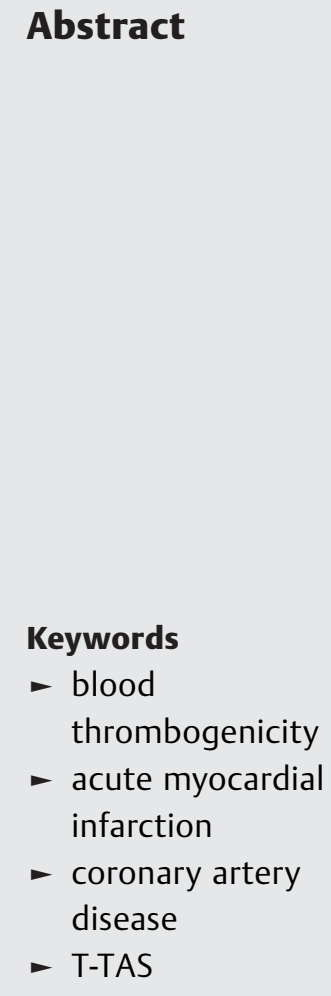

Objective Although blood thrombogenicity seems to be one of the determinant factors for the development of acute myocardial infarction (MI), it has not been dealt with in-depth. This study aimed to investigate blood thrombogenicity and its change in acute MI patients.

Methods and Results We designed a prospective, observational study that included 51 acute Ml patients and 83 stable coronary artery disease (CAD) patients who underwent cardiac catheterization, comparing thrombogenicity of the whole blood between: (1) acute MI patients and stable CAD patients; and (2) acute and chronic phase in MI patients. Blood thrombogenicity was evaluated by the Total ThrombusFormation Analysis System (T-TAS) using the area under the flow pressure curve $\left(A \cup C_{30}\right)$ for the AR-chip. Acute MI patients had significantly higher $A \cup C_{30}$ than stable CAD patients (median [interquartile range], 1,771 [1,585-1,884] vs. 1,677 [1,527$1,756], p=0.010)$. Multivariate regression analysis identified acute $\mathrm{MI}$ with initial TIMI flow grade $0 / 1$ as an independent determinant of high $\mathrm{AUC}_{30}(\beta=0.211, p=0.013)$. In acute MI patients, $A \cup C_{30}$ decreased significantly from acute to chronic phase $(1,859$ $[1,550-2,008]$ to $1,521[1,328-1,745], p=0.001)$.

Conclusion Blood thrombogenicity was significantly higher in acute MI patients than in stable CAD patients. Acute MI with initial TIMI flow grade 0/1 was significantly associated with high blood thrombogenicity by multivariate analysis. In acute MI patients, blood thrombogenicity was temporarily higher in acute phase than in chronic phase.

\section{Introduction}

Acute myocardial infarction (MI) is caused by plaque disruption and subsequent thrombotic coronary occlusion. However, plaque disruptions and mural thrombus formation are often detected in the coronary arteries without causing any

received

September 15, 2021 accepted after revision December 10, 2021
DOI https://doi.org/ 10.1055/a-1719-6178. ISSN 2512-9465. coronary event, that is, silent plaque disruptions. ${ }^{1,2}$ The determinant factors for mural thrombus at disrupted plaque to become occlusive have been unknown.

Blood thrombogenicity is one of the well-known determinant factors of thrombus formation. However, it is not always stable, due to which change is likely to influence the

(C) 2022. The Author(s).

This is an open access article published by Thieme under the terms of the Creative Commons Attribution License, permitting unrestricted use, distribution, and reproduction so long as the original work is properly cited. (https://creativecommons.org/licenses/by/4.0/) Georg Thieme Verlag KG, Rüdigerstraße 14, 70469 Stuttgart, Germany 
development of acute MI. In fact, blood thrombogenicity has been reported to vary under some factors ${ }^{3-5}$ that may trigger the onset of MI. ${ }^{6,7}$ Although a hypothesis that a temporary rise in blood thrombogenicity triggers thrombotic coronary occlusion after plaque disruption has been presented, ${ }^{8}$ it appears not to be adequately established. Previous studies investigated thrombogenic components of blood in MI patients, such as platelet function or coagulation factors activities, and suggested that blood thrombogenicity was temporarily increased in the acute phase of MI patients ${ }^{9-14}$; however, these thrombogenic components only partially reflect thrombogenicity of whole blood, which in acute MI patients has not been adequately elucidated.

The present study therefore aimed to test the following pre-specified hypotheses: (1) that thrombogenicity of whole blood is higher in the patients with acute MI than in those with stable coronary artery disease (CAD); and (2) that thrombogenicity of whole blood in MI patients is temporarily high in the acute phase. We used the Total ThrombusFormation Analysis System (T-TAS; Fujimori Kogyo, Tokyo, Japan) to evaluate thrombogenicity of whole blood under flow conditions. ${ }^{15}$

\section{Material and Methods}

\section{Patients and Study Design}

We designed a prospective, single-center, observational study, in which we enrolled patients with acute MI or stable CAD who received left heart catheterization from August 2018 to September 2020, comparing thrombogenicity of the whole blood between: (1) acute MI patients and stable CAD patients; and (2) acute and chronic phase in MI patients. Acute MI was defined as type $1 \mathrm{MI}$ according to the fourth universal definition of MI. ${ }^{16}$ Stable CAD was defined as asymptomatic or symptomatic CAD with stable symptoms after initial diagnosis or revascularization. Patients using anticoagulants or extracorporeal membrane oxygenation with heparin coating before collection of blood samples were excluded because they were known to affect the measurement by T-TAS. ${ }^{15}$ T-TAS measurement was possible only when its specialist was available. This study (EBTAMI [Evaluation of Blood Thrombogenicity in Acute Myocardial Infarction] Study; UMIN000034196) was approved by the Osaka National Hospital Institutional Review Board \#2 (Approval No. 16016), and all patients signed written informed consent.

\section{Antithrombotic Therapy and Catheterization}

Antiplatelet therapy was performed with aspirin $(100 \mathrm{mg} / \mathrm{d})$ and/or prasugrel $(3.75 \mathrm{mg} / \mathrm{d})$ or clopidogrel $(75 \mathrm{mg} / \mathrm{d})$ as a maintenance dose for patients who had received percutaneous coronary intervention (PCI). In cases of primary PCI, a loading dose of aspirin $(200 \mathrm{mg})$ and prasugrel $(20 \mathrm{mg})$, or clopidogrel (300 mg) was administered to each naïve patient. Intravenous unfractionated heparin $(100 \mathrm{U} / \mathrm{kg})$ was administered at the beginning of catheterization, and an additional dose was repeated to maintain an activated clotting time of $\geq 250$ s during the procedure. GP-IIb/IIIa inhibitors were not used because they were not approved in Japan. Catheterization was performed via radial, brachial, or femoral artery approach using a 6-Fr or 7-Fr sheath and catheters. Coronary angiography was recorded by Artis zee biplane (Siemens Healthineers AG, Erlangen, Germany).

\section{Collection of Blood Samples}

In stable CAD patients and in acute phase MI patients, blood samples were collected before the administration of unfractionated heparin. The administration timing of antiplatelet agents was left to the discretion of attending physician. In MI patients, blood samples were collected again at discharge as the chronic phase. The blood sample was collected into plastic tubes containing 3.2\% sodium citrate (Terumo, Tokyo, Japan). It was allowed to stand for 1 to 3 hours, of which $480 \mu \mathrm{L}$ was mixed with $20 \mu \mathrm{L}$ of $0.3 \mathrm{~mol} / \mathrm{L} \mathrm{CaCl}_{2}$ containing $1.25 \mathrm{mg} / \mathrm{mL}$ of corn trypsin inhibitor immediately before measurement.

\section{Measurement of Thrombogenicity of Whole Blood}

Thrombogenicity of whole blood was determined with TTAS using the AR chip. The AR chip can assess the thrombogenicity of the whole blood associated with both platelets and coagulation systems. The AR chip contains a capillary channel that is $15 \mathrm{~mm}$ long, $300 \mu \mathrm{m}$ in width, and $80 \mu \mathrm{m}$ in depth, coated with type I collagen and tissue thromboplastin. The blood sample is perfused through the capillary by the precision pump with a shear rate of $600 \mathrm{~s}^{-1}$ (a flow rate of $10 \mu \mathrm{L} / \mathrm{min}$ ). After the perfusion of blood initiated, collagen and tissue thromboplastin activate platelets and the extrinsic coagulation pathway. Depending on the formation of thrombus, the capillary is gradually occluded, and the flow pressure monitored by the sensor is increased. The area under the flow pressure curve for the first 30 minutes at a flow rate of $10 \mu \mathrm{L} / \mathrm{min}\left(\mathrm{AUC}_{30}\right.$ ) was used to evaluate blood thrombogenicity. ${ }^{15}$ Prior literatures reported the coefficients of variation for $\mathrm{AUC}_{30}$ in AR-chip analysis as 1.2 to $5.0 \%{ }^{17,18}$

\section{Statistical Analysis}

Continuous variables were expressed as median (interquartile range $[\mathrm{IQR}]$ ) and were compared by Mann-Whitney Utest or Kruskal-Wallis test. Categorical variables were expressed as absolute numbers (percentage) and were compared by the Chi-square test or Fisher's exact test. Wilcoxon signed-rank test was used to compare $\mathrm{AUC}_{30}$ between acute and chronic phases in MI patients. Spearman rank correlation was used to determine the relationship between $\mathrm{AUC}_{30}$ and each variable. Multivariate linear regression analysis was performed to elucidate the factors associated with $\mathrm{AUC}_{30}$, including platelet count, P2Y12 antagonists use, angiotensinconverting enzyme inhibitors/angiotensin II receptor blockers use, beta-blockers use, and acute MI (model 1) or acute MI with TIMI flow grade $0 / 1$ (model 2). Variables with $p<0.10$ by univariate analysis were used for these models. All statistical analysis was regarded as significant when $p$-value was $<0.05$. Statistical analysis was performed by IBM SPSS Statistics 23.0 software (IBM Corp., Armonk, New York, United States). 


\section{Results}

\section{Study Patients}

Included in the analysis were 51 patients with acute MI and 83 patients with stable CAD. Patients' characteristics are presented in - Table 1. Platelet count was higher in the acute MI patients than in stable CAD patients, whereas antiplatelet agents were used more frequently in stable CAD patients than in acute MI patients. There was no significant difference in $\mathrm{AUC}_{30}$ among patients taking no, single, and dual antiplatelet agents both in acute MI patients $(1,794$ [1,598$1,908]$ vs. $1,748[1,560-1,876]$ vs. $1,752[1,255-1,853]$, $p=0.546)$ and in stable CAD patients $(1,593[1,538-1,651]$ vs. $1,727[1,494-1,774]$ vs. $1,681[1,552-1,775], p=0.436)$.

Table 1 Baseline characteristics of patients with acute MI or stable CAD

\begin{tabular}{|c|c|c|c|}
\hline Variables & Acute MI & Stable CAD & $p$-Value \\
\hline Study patients & 51 & 83 & - \\
\hline Age, years & $70(60-79)$ & $71(66-77)$ & 0.615 \\
\hline Male sex & $38(75)$ & $66(80)$ & 0.499 \\
\hline Body-mass index, $\mathrm{kg} / \mathrm{m}^{2}$ & $22.6(20.3-25.0)$ & $24.1(21.7-26.8)$ & 0.011 \\
\hline STEMI & $27(53)$ & - & - \\
\hline Initial TIMI flow grade $0 / 1$ & $22(43)$ & - & - \\
\hline Prior MI & $4(8)$ & $20(24)$ & 0.017 \\
\hline Prior $\mathrm{PCl}$ & $10(20)$ & $50(60)$ & $<0.001$ \\
\hline \multicolumn{4}{|l|}{ Coronary risk factors } \\
\hline Hypertension & $29(57)$ & $58(70)$ & 0.125 \\
\hline Hypercholesterolemia & $28(55)$ & $55(66)$ & 0.188 \\
\hline Diabetes mellitus & $19(37)$ & $34(41)$ & 0.670 \\
\hline Current smoker & $29(57)$ & $25(30)$ & 0.002 \\
\hline \multicolumn{4}{|l|}{ Medical treatment } \\
\hline Aspirin & $35(69)$ & $77(93)$ & $<0.001$ \\
\hline P2Y12 antagonists & $8(16)$ & $70(84)$ & $<0.001$ \\
\hline Beta-blockers & $4(8)$ & $34(41)$ & $<0.001$ \\
\hline ACE-inhibitors/ARB & $14(27)$ & $51(61)$ & $<0.001$ \\
\hline Calcium channel antagonists & $14(27)$ & $37(45)$ & 0.047 \\
\hline Statins & $17(33)$ & $68(82)$ & $<0.001$ \\
\hline Oral hypoglycemic drug & $11(22)$ & $15(18)$ & 0.619 \\
\hline \multicolumn{4}{|l|}{ Laboratory data } \\
\hline Platelet count, $10^{3} / \mu \mathrm{L}$ & $225(191-295)$ & $203(169-231)$ & 0.002 \\
\hline Hematocrit, \% & $40.8(36.3-44.7)$ & $39.9(37.0-42.5)$ & 0.318 \\
\hline CRP, mg/dL & $0.12(0.05-0.53)$ & $0.09(0.03-0.18)$ & 0.022 \\
\hline Total cholesterol, mg/dL & $187(141-227)$ & $157(135-173)$ & $<0.001$ \\
\hline LDL cholesterol, mg/dL & $108(87-143)$ & $79(66-94)$ & $<0.001$ \\
\hline HDL cholesterol, mg/dL & $48(40-56)$ & $49(43-60)$ & 0.381 \\
\hline Triglycerides, mg/dL & $91(57-161)$ & $119(89-154)$ & 0.027 \\
\hline Creatinine, mg/dL & $0.95(0.81-1.22)$ & $0.87(0.74-1.04)$ & 0.083 \\
\hline $\mathrm{HbA}_{1 \mathrm{c}}, \%$ & $6.0(5.6-6.7)$ & $6.1(5.8-6.9)$ & 0.203 \\
\hline $\mathrm{CK}, \mathrm{U} / \mathrm{L}$ & $92(66-208)$ & $104(67-154)$ & 0.576 \\
\hline CK-MB, U/L & $5(4-24)$ & - & - \\
\hline Troponin T, ng/L & $123(40-522)$ & - & - \\
\hline
\end{tabular}

Abbreviations: ACE, angiotensin-converting-enzyme; ARB, angiotensin II receptor blockers; CAD, coronary artery disease; CK, creatine kinase; CRP, Creactive protein; $\mathrm{HbA}_{1 \mathrm{c}}$, glycosylated hemoglobin; $\mathrm{HDL}$, high-density lipoprotein; $\mathrm{LDL}$, low-density lipoprotein; $\mathrm{MI}$, myocardial infarction; $\mathrm{PCl}$, percutaneous coronary intervention; STEMI, ST-segment elevation myocardial infarction.

Note: Categorical variables are described as absolute numbers (\%) and continuous variables are described as median (interquartile range). 


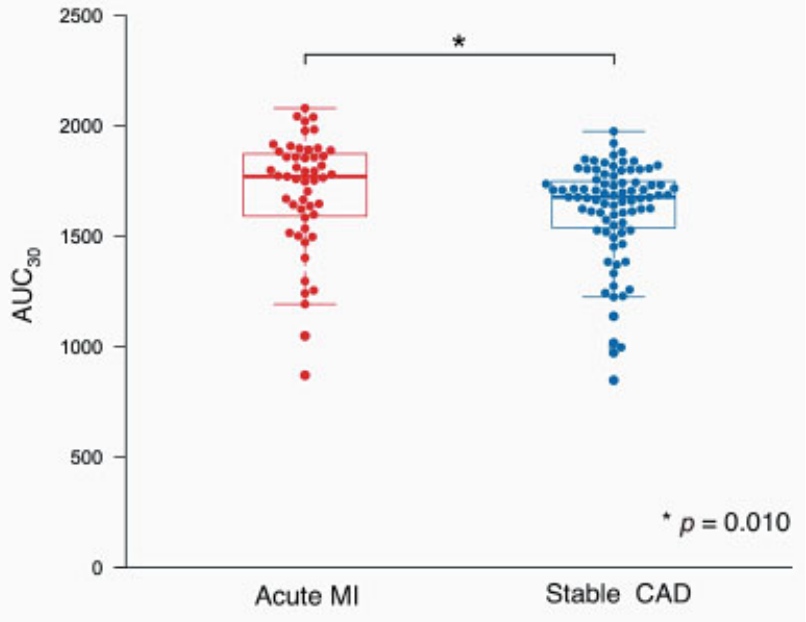

Fig. 1 Comparison of blood thrombogenicity between acute $\mathrm{MI}$ and stable $C A D$. Patients with acute $\mathrm{MI}$ had significantly higher $\mathrm{AUC}_{30}$ levels than those with stable CAD $(1,771[1,585-1,884]$ vs. 1,677 $[1,527-1,756], p=0.010)$. CAD, coronary artery disease; $\mathrm{MI}$, myocardial infarction.

\section{Comparison between Patients with Acute MI and Stable CAD}

Acute MI patients had significantly higher $\mathrm{AUC}_{30}$ than stable CAD patients $(1,771[1,585-1,884]$ vs. 1,677 [1,527-1,756], $p=0.010$; - Fig. 1). Acute MI patients with initial TIMI flow grade $0 / 1$ had significantly higher $A C_{30}$ than stable CAD patients, whereas there was no significant difference in AUC $_{30}$ between acute MI patients with initial TIMI flow grade $2 / 3$ and stable CAD patients $(1,852[1,661-1,910]$ vs. $1,677[1,527-1,756], p<0.001 ; 1,748$ [1,450-1,826] vs. 1,677 [1,527-1,756], $p=0.597$, respectively; - Fig. 2). Multivariate linear regression analysis ( $\mathbf{- T a b l e ~} \mathbf{2}$ ) revealed that an independent determinant of high blood thrombogenicity was acute MI with TIMI flow grade 0/1.

Among 24 non-ST-segment elevation MI patients, six patients had multiple stenotic lesions that might be the possible culprit of MI, in whom the culprit of MI was determined by echocardiographic findings in three patients, by electrocardiographic findings in two patients, and by the flow delay on angiogram in one patient. On the other hand, the rest 18 patients had only one stenotic lesion that can be the culprit of MI. Since the identification of MI culprit might be difficult in some patients with non-ST-segment elevation

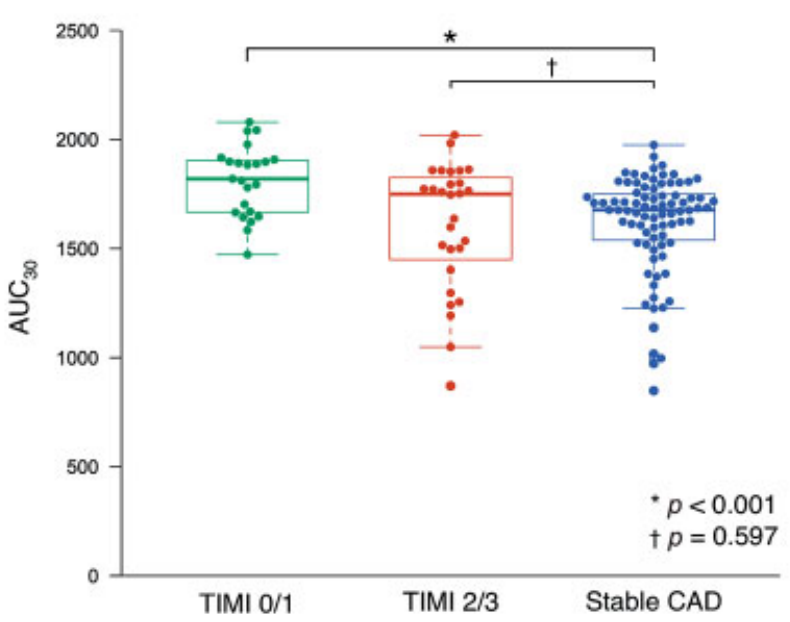

Fig. 2 Comparison of blood thrombogenicity by initial TIMI flow grade in acute MI. Acute MI patients with initial TIMI 0/1 flow grade had significantly higher $A U C_{30}$ levels than stable CAD patients $(1,852$ $[1,661-1,910]$ vs. $1,677[1,527-1,756], p<0.001)$, whereas there was no significant difference in $\mathrm{AUC}_{30}$ levels between acute MI patients with initial TIMI 2/3 flow grade and stable CAD patients $(1,748$ $[1,450-1,826]$ vs. $1,677[1,527-1,756], p=0.597)$. CAD, coronary artery disease; MI, myocardial infarction.

MI, the additional analysis regarding TIMI flow grade was performed with ST-segment elevation MI patients alone. The ST-segment elevation MI patients with TIMI 0/1 $(n=21)$ had significantly higher $\mathrm{AUC}_{30}$ than stable CAD patients, whereas there was no significant difference in $\mathrm{AUC}_{30}$ between STsegment elevation MI patients with TIMI 2/3 $(n=6)$ and stable CAD patients $(1,819[1,656-1,912]$ vs. 1,677 [1,527$1,756], p<0.001 ; 1,636[1,437-1,810]$ vs. 1,677 [1,527$1,756], p=1.000$, respectively). Furthermore, multivariate analysis showed that ST-segment elevation MI with TIMI flow grade $0 / 1$ was an independent determinant of high $\operatorname{AUC}_{30}(\beta=0.193, p=0.024)$. These results were not different from the analysis with all MI patients.

\section{Comparison between the Acute and Chronic Phases in Acute MI Patients}

Both of acute phase and chronic phase T-TAS measurements were available in 13 patients. Baseline characteristics are presented in - Table 3. The measurement interval between acute

Table 2 Multivariate liner regression analysis of determinants of $A \cup C_{30}$ levels

\begin{tabular}{|l|l|l|l|}
\hline Variables & $\beta$ & $95 \% \mathrm{Cl}$ & $p$-Value \\
\hline Model 1 & & & \\
\hline Platelet count & 0.367 & $0.207-0.527$ & $<0.001$ \\
\hline Model 2 & & & \\
\hline Acute Ml with TIMI 0/1 flow grade & 0.211 & $0.044-0.377$ & 0.013 \\
\hline Platelet count & 0.297 & $0.131-0.464$ & 0.001 \\
\hline
\end{tabular}

Abbreviations: $\mathrm{Cl}$, confidence interval; MI, myocardial infarction. 
Table 3 Baseline characteristics of patients with acute MI in the acute or chronic phase

\begin{tabular}{|l|l|l|l|}
\hline Variables & Acute phase & Chronic phase & $p$-Value \\
\hline Medical treatment & & & \\
\hline Aspirin & $9(69)$ & $13(100)$ & 0.125 \\
\hline P2Y12 antagonists & $0(0)$ & $13(100)$ & $<0.001$ \\
\hline Beta-blockers & $1(8)$ & $12(92)$ & 0.001 \\
\hline ACE-inhibitors/ARB & $2(15)$ & $11(85)$ & 0.004 \\
\hline Calcium channel antagonists & $2(15)$ & $0(0)$ & 0.500 \\
\hline Statins & $3(23)$ & $13(100)$ & 0.002 \\
\hline Laboratory data & & & \\
\hline Platelet count, $10^{3} / \mathrm{HL}$ & $240(191-315)$ & $237(212-302)$ & 0.724 \\
\hline Hematocrit, $\%$ & $40.7(38.7-46.0)$ & $38.0(35.6-43.0)$ & 0.009 \\
\hline CRP, mg/dL & $0.18(0.08-0.30)$ & $0.37(0.17-1.39)$ & 0.060 \\
\hline Total cholesterol, $\mathrm{mg} / \mathrm{dL}$ & $204(147-229)$ & $142(131-170)$ & 0.001 \\
\hline LDL cholesterol, $\mathrm{mg} / \mathrm{dL}$ & $136(96-153)$ & $80(71-103)$ & 0.001 \\
\hline HDL cholesterol, $\mathrm{mg} / \mathrm{dL}$ & $47(39-52)$ & $41(35-65)$ & 0.003 \\
\hline Triglycerides, $\mathrm{mg} / \mathrm{dL}$ & $117(43-154)$ & $123(89-134)$ & 0.807 \\
\hline Creatinine, $\mathrm{mg} / \mathrm{dL}$ & $0.89(0.72-1.21)$ & $0.85(0.75-1.07)$ & 0.421 \\
\hline CK, U/L & $80(68-141)$ & $47(35-65)$ & 0.001 \\
\hline
\end{tabular}

Abbreviations: ACE, angiotensin-converting-enzyme; ARB, angiotensin II receptor blockers; CK, creatine kinase; CRP, C-reactive protein; HDL, highdensity lipoprotein; LDL, low-density lipoprotein; MI, myocardial infarction.

Note: Categorical variables are described as absolute numbers (\%) and continuous variables are described as median (interquartile range).

and chronic phase was $13 \pm 5$ days. $\mathrm{AUC}_{30}$ decreased significantly from acute to chronic phase in those patients $(1,859$ $[1,550-2,008]$ to 1,521 [1,328-1,745], $p=0.001 ;$ - Fig. 3).

\section{Discussion}

The present study demonstrated that thrombogenicity of whole blood was significantly higher in acute MI patients,

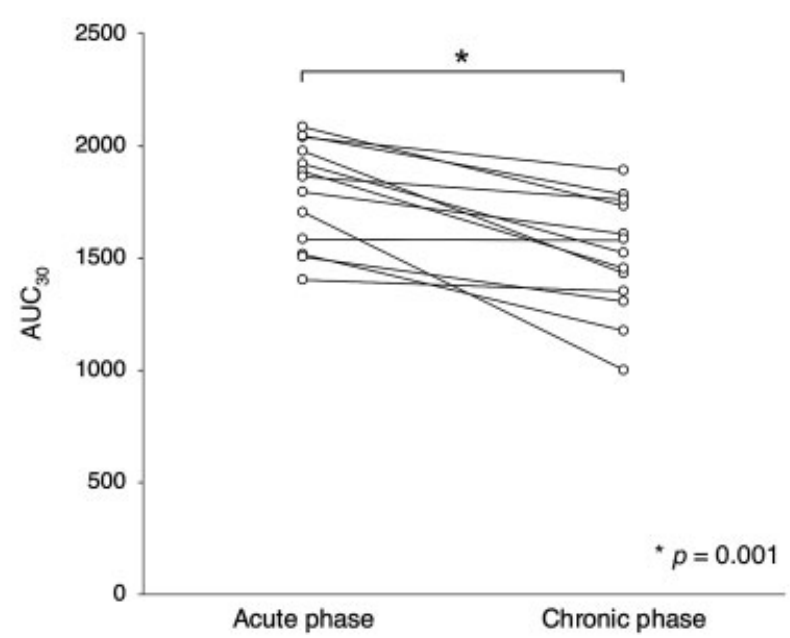

Fig. 3 Serial changes of blood thrombogenicity from the acute to chronic phase in acute MI. AUC 30 levels decreased significantly from acute to chronic phase in patients with acute $\mathrm{MI}(1,859[1,550-2,008]$ to 1,521 $[1,328-1,745], p=0.001)$. MI, myocardial infarction. especially in those with TIMI flow grade $0 / 1$, than in stable CAD patients. Furthermore, blood thrombogenicity decreased significantly from acute to chronic phase among acute MI patients, suggesting that thrombogenicity was temporarily high in the acute phase.

Several studies have demonstrated the association between the onset of MI and coagulation factors. The increased levels of fibrinogen and von Willebrand factor antigen were independent predictors of subsequent acute coronary syndromes in a prospective cohort study with angina pectoris patients. ${ }^{9}$ The increased factor VII, IX, and XI activity, and the decreased levels of antithrombin III and protein $\mathrm{C}$ were detected in the acute phase of MI patients. ${ }^{10-12}$ Moreover, the activation of factor XI and increased serum levels of fibrinopeptide A were temporarily observed in the acute phase of MI patients. ${ }^{13,14}$ On the other hand, factor $X$ did not differ between acute MI and stable CAD patients, ${ }^{11}$ and factor $\mathrm{V}$ and XII were rather reduced in the acute phase of MI patients. ${ }^{10,12}$ Therefore, in those prior studies, thrombogenicity of whole blood cannot be judged from the findings on the individual coagulation factors. The importance and novelty of our study are that whole blood samples under flow conditions mimicking in vivo atherosclerotic lesion were used to investigate the status of blood thrombogenicity in acute MI patients. The present study demonstrated that blood thrombogenicity is temporarily high in the acute phase of MI patients, supporting the hypothesis that a temporary increase in blood thrombogenicity is involved in the development of acute MI. 
We found that MI patients with initial TIMI flow grade 0/1 was independently associated with high $\mathrm{AUC}_{30}$. This finding may be pathophysiologically plausible. High blood thrombogenicity may cause occlusive large and firm thrombus formation leading to TIMI flow grade $0 / 1$; however, relatively low blood thrombogenicity may cause the formation of relatively fragile thrombus leading to spontaneous recanalization with the higher TIMI flow grade, which results in the stronger relationship between $\mathrm{AUC}_{30}$ and TIMI 0/1 acute MI rather than with acute MI in general.

The present study showed that platelet count was also independently associated with $\mathrm{AUC}_{30}$, which was consistent with previous studies. ${ }^{19,20}$ It is controversial whether platelet count is a risk of MI, as some population-based cohort studies have reported high platelet count as a risk of cardiovascular death and cardiovascular disease ${ }^{21,22}$ but others have reported that it is not. ${ }^{23,24}$ However, since acute MI patients had higher platelet count than stable CAD patients and platelet count was independently associated with high blood thrombogenicity in the present study, platelet count would be a risk of MI.

The measurement of blood thrombogenicity by T-TAS using AR chip is known to be affected by anticoagulants, GPIIb/IIIa antagonists, and GPIb $\alpha$ antagonists ${ }^{15,20}$ but not by aspirin and P2Y12 antagonists, i.e., clopidogrel, prasugrel, and ticagrelor. ${ }^{17,19,25,26}$ The reason for this has been mentioned in prior literature that P2Y12 inhibitors may have no effect in AR chip, in which thrombus formation is more dependent upon fibrin formation, as platelets play little in thrombus formation at low shear rates. ${ }^{17}$ AR chip measures the formation of occlusive thrombus in a capillary channel coated with type I collagen and tissue thromboplastin, mimicking the formation of occlusive thrombus in the atherosclerotic artery. Aspirin and P2Y12 inhibitors have an antithrombotic effect through GPIIb/IIIa, which mainly contributes to platelet instability. ${ }^{27}$ Although platelets are generally important for the arterial thrombus formation, thrombus formed at the culprit lesion of MI is mixed thrombus with high fibrin content, ${ }^{28,29}$ suggesting that coagulation system plays an important role in the formation of occlusive thrombus. We therefore believe that the measurement using T-TAS with AR-chip would be appropriate for assessing blood thrombogenicity related to the development of acute MI.

Epidemiologic studies have shown that various factors such as temperature, exercise, and mental stress trigger the onset of $\mathrm{MI}^{6,7}$ and that those factors increase platelet and coagulation activities. ${ }^{3-5}$ Our present study added important evidence for the association between the increase in blood thrombogenicity and acute MI onset. However, further studies are still needed to clarify the mechanisms that contribute to the formation of occlusive thrombus at the thrombogenic vessel wall by which acute MI is caused. The hypothesis ${ }^{30}$ that a temporary increase in blood thrombogenicity is involved in the development of acute MI should also be tested in those studies.

Although AR-chip mimics the formation of occlusive thrombus in the atherosclerotic artery, nobody knows if it is the ideal model for acute MI culprit lesion. The dynamic circadian, daily, or monthly changes of blood thrombogenicity and its determinant factors has not yet been clarified.

\section{Conclusion}

Blood thrombogenicity was significantly higher in acute MI patients than in stable CAD patients. Acute MI with initial TIMI flow grade $0 / 1$ was significantly and independently associated with high blood thrombogenicity by multivariate analysis. Furthermore, in acute MI patients, blood thrombogenicity was temporarily higher in acute phase than in chronic phase.

\section{What Is Known about This Topic?}

- Blood thrombogenicity seems to be one of the determinant factors for mural thrombus at disrupted coronary plaques to become occlusive.

- Acute myocardial infarction is associated with a hypercoagulable state with increased fibrinogen, von Willebrand factor antigen, and factor VII, IX, and XI activity, and decreased antithrombin III and protein C.

\section{What Does This Paper Add?}

- Thrombogenicity of whole blood measured by T-TAS was significantly higher in the patients with acute myocardial infarction than in those with stable coronary artery disease.

- In acute myocardial infarction patients, thrombogenicity of the whole blood was temporarily higher in acute phase than in chronic phase.

\section{Conflict of Interest}

Y.U. received research grants from Abbott Vascular, Pfizer, Bayer, Daiichi Sankyo, Astellas, Shionogi, Sanofi, Ono, Nihon Kohden, Amgen Astellas, Actelion, Bristol-Myers Squibb, Medtronic, AstraZeneca, Otsuka, and Novartis, and lecture fees from Daiichi Sankyo, MSD, Goodman, Sanofi, Mochida, Takeda, Kowa, Teijin, Astellas, Actelion, Bristol-Myers Squibb, AstraZeneca, Boston Scientific, Sumitomo Dainippon Pharma, Eisai, and Amgen Astellas. H.A. received research grants from Daiichi Sankyo and Boehringer Ingelheim. K.I. received manuscript and lecture fees from Daiichi Sankyo, Boehringer Ingelheim, Medtronic, and Johnson \& Johnson. Y.K. received lecture fees from Daiichi Sankyo, Boehringer Ingelheim, Bayer, Bristol-Meyers Squibb, and Pfizer.

Funding

Research grants for this study was provided by Pfizer, Bayer, Daiichi-Sankyo, Astellas, Shionogi, Nihon Kohden, Abbott, and Teijin.

Conflict of Interest

None declared. 
Acknowledgements

None.

\section{References}

1 Davies MJ, Bland JM, Hangartner JRW, Angelini A, Thomas AC. Factors influencing the presence or absence of acute coronary artery thrombi in sudden ischaemic death. Eur Heart J 1989;10 (03):203-208

2 Arbustini E, Grasso M, Diegoli M, et al. Coronary atherosclerotic plaques with and without thrombus in ischemic heart syndromes: a morphologic, immunohistochemical, and biochemical study. Am J Cardiol 1991;68(07):36B-50B

3 Jern C, Eriksson E, Tengborn L, Risberg B, Wadenvik H, Jern S. Changes of plasma coagulation and fibrinolysis in response to mental stress. Thromb Haemost 1989;62(02):767-771

4 Kawahara J, Sano H, Fukuzaki H, Saito K, Hirouchi H. Acute effects of exposure to cold on blood pressure, platelet function and sympathetic nervous activity in humans. Am J Hypertens 1989; 2(09):724-726

5 Patterson SM, Krantz DS, Gottdiener JS, Hecht G, Vargot S, Goldstein DS. Prothrombotic effects of environmental stress: changes in platelet function, hematocrit, and total plasma protein. Psychosom Med 1995;57(06):592-599

6 Smyth A, O'Donnell M, Lamelas P, Teo K, Rangarajan S, Yusuf SINTERHEART Investigators. Physical activity and anger or emotional upset as triggers of acute myocardial infarction: the INTERHEART study. Circulation 2016;134(15):1059-1067

7 Caussin C, Escolano S, Mustafic H, et al; CARDIO-ARSIF Registry Investigators. Short-term exposure to environmental parameters and onset of ST elevation myocardial infarction. The CARDIOARSIF registry. Int J Cardiol 2015;183:17-23

8 Muller JE, Tofler GH, Stone PH. Circadian variation and triggers of onset of acute cardiovascular disease. Circulation 1989;79(04): 733-743

9 Thompson SG, Kienast J, Pyke SDM, Haverkate F, van de Loo JCEuropean Concerted Action on Thrombosis and Disabilities Angina Pectoris Study Group. Hemostatic factors and the risk of myocardial infarction or sudden death in patients with angina pectoris. N Engl J Med 1995;332(10):635-641

10 Vaziri ND, Kennedy SC, Kennedy D, Gonzales E. Coagulation, fibrinolytic, and inhibitory proteins in acute myocardial infarction and angina pectoris. Am J Med 1992;93(06):651-657

11 Minnema MC, Peters RJG, de Winter R, et al. Activation of clotting factors XI and IX in patients with acute myocardial infarction. Arterioscler Thromb Vasc Biol 2000;20(11):2489-2493

12 Moyssakis I, Vlahodimitris IE, Kanakis MA, Kapsimali V, Tsoucala C, Vaiopoulos GA. Behavior of coagulation factors and normal inhibitors of coagulation during the acute phase of myocardial infarction. Blood Coagul Fibrinolysis 2010;21(07):670-673

13 Loeffen R, van Oerle R, de Groot PG, et al. Increased factor XIa levels in patients with a first acute myocardial infarction: the introduction of a new thrombin generation based factor XIa assay. Thromb Res 2014;134(06):1328-1334

14 Merlini PA, Bauer KA, Oltrona L, et al. Persistent activation of coagulation mechanism in unstable angina and myocardial infarction. Circulation 1994;90(01):61-68
15 Hosokawa K, Ohnishi T, Kondo T, et al. A novel automated microchip flow-chamber system to quantitatively evaluate thrombus formation and antithrombotic agents under blood flow conditions. J Thromb Haemost 2011;9(10):2029-2037

16 Thygesen K. 'Ten Commandments' for the Fourth Universal Definition of Myocardial Infarction 2018. Eur Heart J 2019;40(03):226

17 Al Ghaithi R, Mori J, Nagy Z, et al. Evaluation of the Total Thrombus-Formation System (T-TAS): application to human and mouse blood analysis. Platelets 2019;30(07):893-900

18 Yamamoto K, Ito T, Nagasato T, et al. Effects of glycemic control and hypoglycemia on thrombus formation assessed using automated microchip flow chamber system: an exploratory observational study. Thromb J 2019;17:17

19 Mitsuse T, Kaikita K, Ishii M, et al. Total thrombus-formation analysis system can predict 1-year bleeding events in patients with coronary artery disease. J Atheroscler Thromb 2020;27(03): 215-225

20 Idemoto Y, Miura SI, Norimatsu K, et al. Evaluation of the antithrombotic abilities of non-vitamin $\mathrm{K}$ antagonist oral anticoagulants using the Total Thrombus-formation Analysis System $^{\circledR}$. Heart Vessels 2017;32(03):309-316

21 Thaulow E, Erikssen J, Sandvik L, Stormorken H, Cohn PF. Blood platelet count and function are related to total and cardiovascular death in apparently healthy men. Circulation 1991;84(02): 613-617

22 Vinholt PJ, Hvas AM, Frederiksen H, Bathum L, Jørgensen MK, Nybo M. Platelet count is associated with cardiovascular disease, cancer and mortality: a population-based cohort study. Thromb Res 2016;148:136-142

23 Folsom AR, Wu KK, Rosamond WD, Sharrett AR, Chambless LE. Prospective study of hemostatic factors and incidence of coronary heart disease: the Atherosclerosis Risk in Communities (ARIC) Study. Circulation 1997;96(04):1102-1108

24 Klovaite J, Benn M, Yazdanyar S, Nordestgaard BG. High platelet volume and increased risk of myocardial infarction: 39,531 participants from the general population. J Thromb Haemost 2011;9(01):49-56

25 Arima Y, Kaikita K, Ishii M, et al. Assessment of platelet-derived thrombogenicity with the total thrombus-formation analysis system in coronary artery disease patients receiving antiplatelet therapy. J Thromb Haemost 2016;14(04):850-859

26 Clifford CR, Jung RG, Hibbert B, et al. Dual antiplatelet therapy (PEGASUS) vs. dual pathway (COMPASS): a head-to-head in vitro comparison. Platelets 2021;00:1-6

27 Brass LF, Zhu L, Stalker TJ. Minding the gaps to promote thrombus growth and stability. J Clin Invest 2005;115(12):3385-3392

28 Sato Y, Hatakeyama K, Yamashita A, Marutsuka K, Sumiyoshi A, Asada Y. Proportion of fibrin and platelets differs in thrombi on ruptured and eroded coronary atherosclerotic plaques in humans. Heart 2005;91(04):526-530

29 Yamashita A, Sumi T, Goto S, et al. Detection of von Willebrand factor and tissue factor in platelets-fibrin rich coronary thrombi in acute myocardial infarction. Am J Cardiol 2006;97(01): 26-28

30 Ueda Y, Kosugi S, Abe $\mathrm{H}$, et al. Transient increase in blood thrombogenicity may be a critical mechanism for the occurrence of acute myocardial infarction. J Cardiol 2021;77(03):224-230 